\title{
A Preliminary Study to Investigate the Prevalence of Pain in Competitive Showjumping Equestrian Athletes
}

\author{
Lewis $\mathrm{V}^{1 *}$, Dumbell $\mathrm{L}^{2}$ and Magnoni $\mathrm{F}^{2}$ \\ ${ }^{1}$ Equestrian Performance Research and Knowledge Exchange Arena, University Centre Hartpury, UK
}

Submission: May 18, 2018; Published: May 29, 2018

*Corresponding author: Lewis V, Equestrian Performance Research and Knowledge Exchange Arena, University Centre Hartpury, UK, Tel: +447813791538; Email: Victoria.lewis@hartpury.ac.uk

Abstract

The aim of the study was to investigate the prevalence of equestrian showjumping riders competing with pain, the location of their pain, factors affecting their pain and whether they perceived this pain to have an effect on their performance. Eighty questionnaires, containing thirtyfour questions, were competed by competitive showjumping riders. There was no association between age and reporting of pain $\left(\mathrm{X}^{2}{ }_{1}=-0.165\right.$, $\mathrm{p}=0.114)$.

Participants were 1.42 times more likely to experience pain than to be pain free. Those riders that competed solely in the discipline of showjumping were 2.2 times more likely to be experiencing chronic pain than acute pain. A highly significant association was found between years of riding and pain $\left(\mathrm{X}^{2}{ }_{1}=-294, \mathrm{p}=0.004\right.$,). Eighty-five percent of participants reported experiencing neck and back pain, with the majority experiencing lower back pain. Sixty-six percent of participants reported experiencing pain in other regions of the body, with the knee being the most common. Sixty-seven percent used over the counter medication with only $9 \%$ using prescription medication to manage their pain. Eightyfive percent of riders perceived their pain to impact on their riding performance. Most commonly they believed that it affected their postural asymmetry ( $45 \%$ ) and reduced their range of motion (36\%). Only $14 \%$ of participants directly reported it affecting the horse by causing asymmetry. The high incidence of showjumping riders who compete with pain, particularly back pain, could be problematic given the longevity of a rider's career, which can span over four decades. This research reports rider's perceptions and self-reported pain and management options, which may affect the data. Further research is needed to establish the causes of back pain and appropriate management strategies.

Keywords: Equestrian; Showjumping; Riders; Chronic pain; Back pain

Abbreviations: OTC: Over-The-Counter; NSAIDs: Non-Steroid Anti-Inflammatory Drugs; WADA: World Anti-Doping Agency; GI: Gastro Intestines

\section{Introduction}

Due to the unpredictable nature of a $500 \mathrm{~kg}$ animal capable of travelling at speeds of $65-75 \mathrm{kmh}^{-1}$ [1] horse riding has a high injury risk; arguably making it one of the most dangerous sporting activities to participate in [2,3]. The hospitalisation rate for equestrian activity is 49 hospital visits for every 1000 hours of riding compared to rugby that has a hospital rate of 93 per 1000hours [4]. Most injuries occur as a result of falling off the horse whilst riding [1,5] and the more severe injuries often occur during a fall whilst jumping fences [6,7]. There have been sixty reported deaths occurring during jumping competitions between 1993 and 2017 which has encouraged the governing bodies of equestrian sports to work to improve safety standards $[8,9]$.

Ball et al. [10] identified that over half of riders that had been hospitalized due to an acute riding injury, experienced chronic physical difficulties following their accident including chronic pain, weakness, decreased balance, headaches, limited use of limbs, decreased memory and mood changes. Whilst acute injuries resulting from horse riding have been documented, evidence is mainly anecdotal suggesting that musculoskeletal injuries arising from overuse could result in riders experiencing chronic pain. Horse riders are at a greater risk of experiencing chronic pain particularly back pain that the non-equestrian population $[11,12]$. This may be due to the repetitive nature of riding and/or as a longer-term consequence of an acute riding injury.

Research has examined the chronic pain experience by equestrian athletes competing in Dressage [12] and Elite Eventing [13] but to date there have been no published studies investigating pain experienced by equestrian athletes competing in showjumping. The demands placed on the rider do differ between disciplines both in terms of physiological demands and biomechanical skill [14]. The aim of the study was to investigate the prevalence of competitive showjumping athletes who experience pain, the location of their pain, factors affecting their pain and whether they perceive this pain to effect on their riding performance. 


\section{Materials and Methods}

A six part 34 question on-line survey (Survey monkey) was made available to equestrian athletes who competed in showjumping, and who were aged eighteen years and over following full institutional ethical approval. The on-line survey was accessible for a 1 month period and no incentive was offered to participants. An online survey was chosen as they reduce time, cost and potential error arising from the transcription of paper questionnaires, in addition to allowing participants to respond at their convenience [15]. Volunteer participants were recruited from personal contacts via email and number of specialist equestrian social media sites (such as the Horse \& Hound forum) was identified and a link to the survey was posted on these sites. A snowball sampling technique was employed where those receiving an email regarding the survey were asked to send on the email to other female horse riders that they knew. Due to the anonymity of the survey, completion of the form was considered as consent to take part in the study (as explained to them in the participant information sheet preceding the survey).

\section{Measure}

A survey was constructed using the principles put forward by Diem [16]. The survey containing twenty questions was developed containing a mixture of closed - response (e.g. Yes/ no and Likert scale) and open-response items designed to take no longer than 10 minutes to complete. Section 1 asked respondents to state their eventing competition level. Section 2 asked questions related to previous injury and self reported level of pain (adapted from validated questions taken from shortform McGill Pain Questionnaire [17], location and cause of this pain. Section 3 was specific to the perceived impact this pain had on their performance. Section 4 asked what factors contributed

Results

\section{Participants}

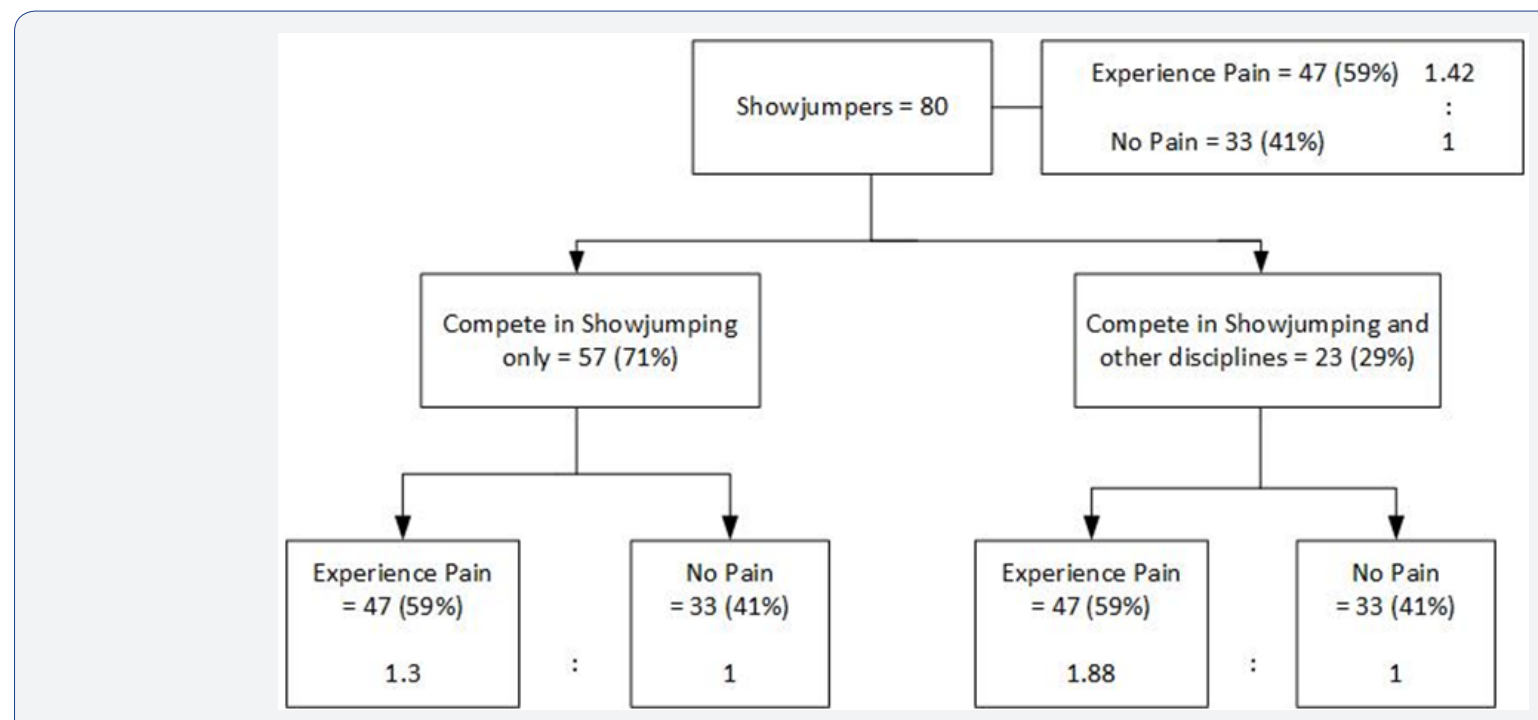

to increased levels of pain when riding (e.g. saddle, movement of the horse, cold weather, yard work). Information related to the participants management strategies for dealing with this pain (e.g. over the counter pain medication, prescription pain medication, manual therapy such as physical therapy, chiropractic treatment and other strategies) was also gathered. The final section (5) was modified for equestrian athletes from the Oswestry pain questionnaire [18] to assess the impact their pain has on their general life and wellbeing. Validity evidence for the instrument was provided by reviewing the questionnaire for: (1) clarity of wording, (2) use of standard English and spelling (3) reliance of items, (4) absence of biased words and phrases, (5) formatting of items, and (6) clarity of instructions [19]. Two faculty senior academics experienced in survey design, were asked to use these guidelines to review the instrument. Based on the reviewers' comments the instrument was revised and as a pilot study the questionnaire was distributed to 10 riders before further revisions were made prior to final administration.

\section{Data Analysis}

In total there were 110 survey responses; however of these only 91 identified that showjumping was their main riding discipline. Eleven participants did not complete the survey fully. As such, the data for the remaining 80 participants met the inclusion criteria for data analysis and the remaining 30 responses were discounted. Data from the Survey monkey $\rightarrow$ package were downloaded into a Microsoft Excel (2010) spreadsheet. Descriptive statistics were used to report frequencies and percentages within data. The Chi-squared test and odds ratios were utilized to assess prevalence of pain experienced by showjumping riders. An alpha value was set at $\mathrm{p}<0.05$ (confidence interval 95\%) throughout unless otherwise stated. Data were analysed using SPSS for Windows version 24 .

Figure 1: The self-reported pain experienced by Showjumpers. 
The 80 showjumping participants had a median age of 23 years (Interquartile range from 20 to 31 years). The majority of participants (89\%) were female and only $11 \%$ were male. The majority of participants (70\%) self- described as amateur competitive riders, with $12.5 \%$ described as recreational riders and $17.5 \%$ self-described as professional riders. Figure 1 describes the pain reported by the participants, with a participant being 1.42 times more likely to experience pain than to be pain free.

\section{Participants Self-Reporting Pain}

A participant was twice as likely (2.0 times) to be experiencing chronic pain (67\%) as acute pain (33\%). If they solely competed in showjumping this odds ratio increased to
2.2 times more likely to be experiencing chronic pain than acute pain. Participants who competed in other disciplines as well as showjumping were 1.5 times more likely to be experiencing chronic pain compared to acute pain.

Ofthe participants reporting pain, 85\% reported experiencing neck and back pain. The majority of these experienced lower back pain. $66 \%$ of participants reported experiencing pain in other regions of the body, with the knee being the most common. Table 1 displays the location and level of pain experienced by participants. The majority of pain was described as being mild, however participants experiencing hip and upper back pain had median levels of moderate pain. Some participants did report severe pain.

Table 1: Location, level and duration of pain experienced by showjumpers.

\begin{tabular}{|c|c|c|c|c|}
\hline Location of Pain & Participants & Median Level of Pain & Highest Level of Pain & $\begin{array}{c}\text { Median Pain Duration } \\
\text { (Years) }\end{array}$ \\
\hline Lower back & $29(62 \%)$ & Mild & Severe & $2-3$ \\
\hline Knee & $22(47 \%)$ & Mild & Severe & $2-3$ \\
\hline Ankle & $17(36 \%)$ & Mild & Severe & $2-3$ \\
\hline Neck & $15(32 \%)$ & Mild & Severe & $4-5$ \\
\hline Hip & $13(28 \%)$ & Moderate & Moderate & $2-3$ \\
\hline Upper back & $11(23 \%)$ & Moderate & Mild & $2-3$ \\
\hline Elbow & $7(15 \%)$ & Mild & Mild & $4-5$ \\
\hline Head & $6(13 \%)$ & Mild & Mild & $4-5$ \\
\hline Wrist & $6(13 \%)$ & Mild & 4 \\
\hline
\end{tabular}

The median durations of pain experienced all exceeded two years, with participants reporting neck, elbow, head and wrist pain reporting median durations of four to five years. Only $15 \%$ of those reporting pain had had a medical diagnosis. Only 15\% of those reporting pain said that it has prevented them from riding, for durations ranging from the occasional day periodically to a whole year. $85 \%$ of participants reported that their experience of pain did not stop them riding.

$30 \%$ of participants with pain did not report any method of management or treatment. The majority, $70 \%$ reported that they did try to manage or treat their pain. The most common method participants reported using to manage or treat their pain was over the counter medication. $67 \%$ of those using a management or treatment method used over the counter medication with only $9 \%$ using prescription medication. $47 \%$ reported using a manipulative therapy to manage or treat the pain, most commonly physiotherapy. $25 \%$ utilised an exercise programme to manage or treat the pain.

There was no association between age and report of pain $\left(\mathrm{X}_{1}^{2}=-0.165, \mathrm{p}=0.114\right)$. A highly significant association was found between years of riding and pain $\left(X^{2}{ }_{1}=-294, p=0.004\right)$. $85 \%$ percent of riders perceived their pain to impact on their riding performance. Most commonly they believed that it affected their postural asymmetry (45\%), followed by reducing their range of motion (36\%), causing fatigue (24\%), affecting mood by increasing anxiety and irritability (21\%), and reducing concentration (19\%). Only $14 \%$ of participants directly reported it affecting the horse by causing asymmetry.

\section{Discussion}

This is a preliminary and exploratory study, using a purposeful sample. The study identified that $61 \%$ of competitive showjumpers competing at the novice to sub-elite level were experiencing pain. This was lower than was seen in elite dressage riders [12] and elite event riders [13]. Chronic injury is a common cause of early retirement from sport $[20,21]$, however there is little evidence to suggest this is a problem within the sport of showjumping. As with other equestrian sports, showjumping is considered an early start, late maturation sport [22], where the mean age of British Olympic showjumping riders in the twenty-first century is forty four years old [23]. It appears that many showjumping riders, such as Olympic Gold Medallist Nick Skelton, who won the gold medal at Rio at the age of sixty despite being in chronic pain after several serious injuries including a broken neck, continue to ride and compete. Lewis \& Kennerley [12] and Lewis \& Baldwin [13] found a significant relationship between elite equestrian athletes' pain and their perception that this pain effected their riding performance. Douglas et al. [14], suggested that riders often do not consider 
themselves as the athlete within the unique dyad relationship that they have with their horse and if the horse is not injured then pain they experience is not a reason for rest, rehabilitation or even retirement from the sport.

In this current study eighty-five percent of riders believed that the pain affected negatively on their riding performance by effecting their posture, increasing fatigue, reducing their range of movement and effecting their concentration. Posture is a key element in any equestrian discipline where the rider aims to maintain a straight line running through the ear-shoulderhip-heel whilst moving in rhythm and harmony with the horse's movement [24-27]. To maintain this position requires stabilization and isometric contraction of the core muscles [28] are needed to enable the trunk to return to equilibrium after perturbation. In order to control the horse the rider must be able to apply individual hand and leg 'aids' or signals by disassociation movements of the arms and legs. Injury or damage to the 'core' muscle groups can result in chronic lower back pain. $86 \%$ of riders in this study reported lower back pain suggesting that the cyclic nature of riding may damage these soft tissue structures [11] and that pain in these structures may have and impact of postural control whist riding. The activity of jumping requires the rider to alter or adjust their position by adopting a forward seat in order to cope with the increased mechanical forces involved. During jumping, the rider closes the hip and thigh angle and moves the trunk into a more forward position. In order to maintain their balance through the jumping phase the rider's weight is absorbed by the legs, as opposed to pelvis and legs as seen in the regular riding position $[14,29,30]$. This adjustment in position requires a great deal of control of the body segments as the rider has to deal with acceleration forces from the horse particularly on landing [30]. Any restriction in the rider's range of movement as a result of pain will effect their position over the fence and will impact on the performance of the horse. Riders also stated that the pain effected their levels of fatigue. Nadler [31]; Kankaanpaa et al., [32] and McGill [33] identified poor endurance in hip extensor muscles (Gluteus maximus) and hip abductors (Gluteus medius), key muscles used to maintain an effective riding position, in individuals that had chronic LBP, suggesting a link between fatigue in these muscle groups and pain.

Participants also noted that the pain affected their concentration. In showjumping riders are required to ride from memory a set pattern of fences of up to 15 obstacles, some with multiple jumping elements, usually with several changes of direction. Failure to jump the fences in the correct order results in an elimination [34]. Equestrian athletes must also process many variables from the horse and environment including speed, stride length, straightness, quality of the gait, ground conditions, type of fence, height of fence etc. in order to position the horse in the optimal take off zone to jump the fence cleanly. Failure to process this information and to make correct decision could result in the horse knocking the fence down (4 faults) or refusing to jump the fence (4 faults) Therefore, any disturbance to the rider's concentration caused by pain may effect performance and safety of horse or rider.

The majority of showjumpers in the study employed pain management strategies. The most common strategy was the use of over-the-counter (OTC) non-steroid anti-inflammatory drugs (NSAIDs) such as aspirin, paracetamol and ibuprofen. Only $9 \%$ of showjumping riders used prescription, which is consent with results found in dressage and event riders $[12,13]$. NSAIDs are widely used in other [35-37], in part due to the ease, cost and accessibility of these drugs. Berglund and Sundgot-Borgen [38], exterminated that sporting athletes use NSAIDs six to ten times more often than the general population, this puts sports people at the potential risk of over mediating or over reliance on pain medication to continue training or competing. The use of self-medicating NSAIDs puts the rider showjumping rider at risk of non-compliance with the World Anti-Doping Agency (WADA) regulations and also the potential risk of side effects of these drugs. Frequent use of NSAID can cause damage to the cardiovascular system, gastro intestines (GI), kidneys and liver [35-37,39]. Following one month regular use of NSAIDs users have a higher relative risk of bleeding in the upper GI tract, other side effects include dyspepsia, nausea, ulcers [40-96].

\section{Conclusion}

This study using a small sample of equestrian athletes established that there is a high incidence of showjumpers who compete with pain, particularly back and neck pain. This is of some concern giving how long a showjumper can participate in the sport, which can span several decades. Participants reported that this pain effected their posture whilst riding, reduced their range of motion, caused fatigue, effecting mood by increasing anxiety and irritability, and reducing their concentration, all of which is likely to impact on both performance and safety. Despite pain experienced and effect on performance a large number of equestrian athletes continued to compete. Athletes self-medicating using NSAIDs could be putting themselves at an increased risk of long-term health issues. This research reports athlete's perceptions and self-reported pain and management options, which may affect the data. Further research is needed to establish the causes of pain and appropriate management strategies.

\section{Acknowledgement}

The authors would like to acknowledge those who kindly took the time to participate in the study.

\section{References}

1. Ball CG, Ball JE, Kirkpatrick AW, Mulloy RH (2007) Equestrian injuries: Incidence, injury patterns, and risk factors for 10 years of major traumatic injuries. The American Journal of Surgery 193(5): 636-640.

2. Norwood S, McAuley C, Vallina VL, Fernandez LG, McLarty JW, et al. (2000) Mechanisms and patterns of injuries related to large animals. Journal of Trauma and Acute Care Surgery 48(4): 740-744. 
3. Sorli JM (2000) Equestrian injuries: A five year review of hospital admissions in British Columbia, Canada. Injury Prevention 6(1): 59-61.

4. Stokes K (2015) RFU Community rugby injury and suveillance and prevention project 2014-2015. English Rugby Union.

5. Mayberry JC, Pearson TE, Wiger KJ, Diggs BS, Mullins RJ (2007) Equestrian Injury Prevention Efforts Need More Attention to Novice Riders. Trauma and Acute Care Surgery 62(3): 735-739.

6. Whitlock MR (1999) Injuries to riders in the cross-country phase of eventing: The importance of protective equipment. British Journal of Sports Medicine 33(3): 212-214.

7. Murray JK, Singer ER, Morgan KL, Proundman CJ, French NP (2006) The risk of a horse-and-rider partnership falling on cross-country phase of eventing competition. Equine Veterinary Journal 38(2): 158163

8. British Eventing (2017) Cross-country for eventers. Warwickshire.

9. FEI (2017) FEI Eventing Cross Country Design Guidelines. Switzerland p. 1-25.

10. Ball J, Ball C, Mulloy R, Datta I, Kirkpatrick A (2009) Ten years of major equestrian injury: Are we addressing functional outcomes? Journal of Trauma Management and Outcomes 3: 2.

11. Kraft CN, Urban N, Ilg A, Wallny T, Scharfstädt A, et al. (2009). Influence of the riding discipline and riding intensity on the incidence of back pain in competitive horseback riders. Sportverletzung Sportschaden 21(1): 29-33.

12. Lewis V, Kennerley R (2017) A preliminary study to investigate the prevalence of pain in elite dressage riders during competition in the United Kingdom. Journal of Comparative Exercise Physiology 13(4): 259-263.

13. Lewis V, Baldwin K (2018) A preliminary study to investigate the prevalence of pain in international event riders during competition, in the United Kingdom. Journal of comparative Exercise Physiology.

14. Douglas JD, Price M, Peters DM (2012) A Systemic Review of Physical Fitness, Physiological Demands and Biomechanical Performance in Equestrian Athletes. Comparative Exercise Physiology 8(1): 53-62.

15. Vehvar, Manfreda (2008) Overview: Online surveys. In: N Fielding, RM Lee, G Blank (Eds); The SAGE Handbook of Online Reseach Methods, SAGE Publications, London, pp.177-194.

16. Diem KG (2002) A step-by-step guide to developing effective questionnaires and survey procedures for program evaluation and research. Rutgers-Cook College Resource centre p.1-5.

17. Melzack R (1987) The short form McGill Pain Questionnaire. Pain 30: 191-197.

18. Fairbank JC, Pyncent PB (2000) The Oswestry Disability Index. Spine 25(22): 2940-2952.

19. Fowler J (2002) Survey Research Methods. Sage Publications.

20. Cook JL, Khan K, Harcourt PR, Grant M, Young DA, et al. (1997) A cross sectional study of 100 athletes with jumper's knee managed conservatively and surgically. The Victorian Institute of Sport Tendon Study Group. British Journal of Sports Medicine 31(4): 332-336.

21. Kettunen JA, Kirst M, Erkki A (2002) Long-Term Prognosis for Jumper's Knee in Male Athletes: Prospective Follow-up Study. American Journal of Sports Medicine 30(5): 689-692.

22. British Equestrian Federation (2015) Long- term participant development for equestrian riders, drivers and vaulters. In: Bruce I (2008) Questionnaire Design: How to Plan, Structure and Write Survey Material for Effective Market Research pp.305.

23. Dumbell L, Douglas J, Rowe L (2017) Demographic Profiling of British
Olympic Equestrian Athletes in the Twenty-First Century. Sport in Society: culture, commerce, media, politics.

24. Hobbs SJ, Baxter J, Broom L, Rossell LD, Sinclair J, et al. (2014) Posture, Flexibility and Grip Strength in Horse Riders. Journal of Human Kinetics 42: 113-125.

25. Münz A, Eckardt F, Witte K (2014) Horse rider interaction in dressage riding. Human movement science 33: 227-237.

26. Lagarde J, Kelso JA, Peham C, Licka T (2005) Coordination dynamics of the horse rider system. Journal of Motor Behaviour 37(2): 418-424.

27. Symes D, Ellis R (2009) A preliminary study into rider asymmetry within equitation. The Veterinary Journal 181(1): 34-37.

28. Terada K, Mullineaux D, Lanovaz J, Kato K, Clayton H (2004) Electromyographic analysis of the riders muscles at trot. Equine and Comparative Exercise Physiology 1(3): 193-198.

29. Nankervis K, Dumbell L, Herbert L, Winfield J, Guire R, et al. (2015) A comparison of the position of elite and non elite riders during competitive show jumping. Comparative Exercise Physiology 11(2): 119-125.

30. Patterson M, Doyle J, Cahill E, Caulfield B, Persson UM (2010) Quanitifying show jumping horse rider expertise using IMUs. In: Proceedings of the Annual International Conference of IEE Engeneeing in Medicine and Biological Society pp.684-687.

31. Nadler SF, Malonga GA, DePrince M, and Feinberg JH (2000) The Relationship Between Lower Extremity Injury, Low Back Pain, and Hip Muscle Strength in Male and Female Collegiate Athletes. Clinical Journal of Sports Medicine 10(2): 89-97.

32. Kankaanpaa M (1998) Back and hip extensor fatigability in chronic low back pain patients and controls. Archives of Physical Medicine and Rehabilitation 79(4): 412-417.

33. McGill S (1997) The biomechanics of lower back pain: Implications on current practice in industry and clinic. Journal of biomechanics $30(5)$ : 465-475.

34. FEI (2018) Eventing Rules 2018. Federation Equestre Interantionale, Switzerland.

35. Ziltener JL, Leal S, Fournier PE (2010) Non-steroidal anti-inflammatory drugs for athletes: An update. Annals of Physical and Rehabilitation Medicine 53(4): 278-288.

36. Warner DC, Schnepf G, Moilanen E (2007) Prevalence, attitudes, and behaviors related to the use of nonsteroidal anti-inflammatory drugs (NAIDs) in student athletes. Journal of Adolescent Health 30(3): 150153.

37. Tricker R (2000) Painkilling drugs in collegiate athletics. Journal of Drug Education 30(3): 313-324.

38. Berglund B, Sundgot Borgen J (2001) Explores the use of medical substances and nutritional supplements (NS) among athletes in the Olympic games in 1996, 1998 and 2000. Types of NS used by athletes; Percentage of athletes who use non-steroid anti-inflammatory drugs (NSAIDS); Benefits of NSAIDS and NS to athletes. Scandinavian Journal of Medicine and Science in Sports 11(6): 369-371.

39. Bjarnason I, Hayllar J, Macpherson AJ, Russell AS (1993) Side Effects of Nonsteroidal Anti-inflammatory Drugs on the Small and Large Intestine in Humans. Gastoenternology 104(6): 1832-1847.

40. Anderson, GBJ (1999) Epidemilogical features of chronic low-back pain. Lancet 354(9178): 581-85.

41. Ariëns GAM, Bongers PM, Douwes M, Miedema MC, Hoogendoorn WE, et al. (2001) Are neck flexion, neck rotation, and sitting at work risk factors for neck pain? Results of a prospective cohort study Occupation Environment Medicine 58(3): 200-207. 
42. Baker JG, Ledddy JJ, Darling SR, Schard J, Makdissi M, et al. (2016) Gender differences in recovery from sports-related concussion in adolescents. Clinical Pediatrics 55(8): 771-775.

43. Balagué F, Mannion AF, Pellisé F, Cedraschi C (2012) Non-specific low back pain. The Lancet 379(9814): 482-491.

44. Balyi I, Way R, Higgs C (2013) Long-term athlete development. Human Kinetics, USA.

45. Bompa T (1999) Periodization training for sport. Human Kinetics, USA.

46. Boschma A, Smith G, Lawson L (1996) Breast support for the active woman: Relationship to 3D kinematics of running. Medicine and Science in Sports and Exercise 26: 99.

47. Burbage J, Cameron L, Goater F (2016) The effect of breast support on vertical breast displacement and breast pain in female riders across equine simulator gaits. Journal of Veterinary Behavior: Clinical Applications and Research 15: 81.

48. Burbage J, Cameron L (2017) An investigation into prevalence and impact of breast pain, bra issues and breast size on female horse riders. Journal of Sport Sciences 35(11): 1091-1097.

49. Chiro trust (2018) 10 facts you should know about whiplash (part 1). United States.

50. Clarsen B (2015) Overuse injuries in sport: Development, validation and application of a new surveillance method. Norway.

51. Clayton NK, Pennekamp PH, Becker U, Young M, Diedrich O, et al. (2009) Magnetic Resonance Imaging Findings of the Lumbar Spine in Elite Horseback Riders Correlations With Back Pain, Body Mass Index, Trunk/Leg-Length Coefficient, and Riding Discipline. The American Journal of Sports Medicine 37(11): 2205-2213.

52. Côté P, Carroll Lj, Carragee EJ, Nordin M, Guzman J (2008) The Burden and Determinants of Neck Pain in Workers. European Spine Journal 17(1): 60-74.

53. Edwards JC and Bodle JD (2014) Causes and consequences of sports concussion. The Journal of Law Medicine \& Ethics 42(2): 128-132.

54. Ekberg J, Toomas T, Henrik R, Lars V (2011) Injury rates and riskfactors associated with eventing: A total cohort study of injury events among adult Swedish eventing athletes. International Journal of Injury Control \& Safety Promotion 18(4): 261-267.

55. Feucht CL, Patel DR (2010) Analgesics and Anti-inflammatory Medications in Sports: Use and Abuse. Pediatric Clinics of North America 57(3): 751-774.

56. Gehlsen G, Albohm M (1980) Evaluation of sports bras. Physician and Sports medicine 10(10): 89-96

57. Hasler RM, Gysssler L, Benneker L, Martinolli L, Schotzau A, et al. (2011) Protective and risk factors in amateur equestrians and description of injury patterns: A retrospective data analysis and a case - control survey. Journal of Trauma Management and Outcomes 5: 4.

58. Hogg Johnson S, Holm LW, Guzman J, Ammendolia C, Nordin M (2008) The Burden and Determinants of Neck Pain in the General Population. European Spine Journal 17(1): 39-51.

59. Johansson B, Wentzel AP, Andréll P, Mannheimer C, Rönnbäck L (2014) Evaluation Effects of Methylphenidate on Posttraumatic Brain Injury Symptoms with Focus on Mental Fatigue and Pain. Brain Injury 28(56): 573-573.

60. Johnson RS, Provenzano MK, Shumaker LM, Valovich McLeod TC, Welch BC (2016) The Effect of Cognitive Rest as Part of Post-Concussion Management for Adolescent Athletes: A Critically Appraised Topic. Journal of sport rehabilitation 26(5): 437-446.

61. Jordan KP, Kadman UT, Hayward R, Porcheret M, Young C, et al. (2010) Annual consultation prevalence of regional musculoskeletal problems in primary care: An observational study. BMC Musculoskeletal Disorders 11: 144.

62. Kasch H, Stengaard Pedersen K, Arendt Nielsen L (2001) Headache, neck pain, and neck mobility after acute whiplash injury. Spine 26(11): 1246-1251.

63. Kraft CN, Pennekamp PH, Becker U, Young M, Diedrich O, et al. (2007) Magnetic Resonance Imaging Findings of the Lumbar Spine in Elite Horseback Riders Correlations with Back Pain, Body Mass Index, Trunk/Leg-Length Coefficient, and Riding Discipline. The American journal of sports medicine 37(11): 2205-2213.

64. Kujala UM, Sarna S, Kaprio J (2005) Cumulative incidence of Achilles tendon rupture and tendiopathy in male former elite athletes. Clinical Journal of Sports Medicine 15(3): 133-135.

65. Loder RT (2008) The Demographics of Equestrian-Related Injuries in the United States: Injury Patterns, Orthopedic Specific Injuries, and Avenues for Injury Prevention. Journal of Trauma and Acute Care Surgery 65(2): 447-460.

66. Maffulli N (2005) Equestrian Injuries. Epidemilogy of Paediatric Sports Injuries 48: 8-17.

67. Moss PA, Wan A, Whitlock MR (2002) A changing pattern of injuries to horse riders. Emergency Medicine Journal 19(5): 412-414.

68. Munsters CC, Visser KE, Van den Broek J, Van Oldruitenborgh, Oosterbaan MMS (2012) The influence of challenging objects and horse-rider matching on heart rate, heart rate variability and behavioural score in riding horses. The Veterinary Journal 192(1): 7580.

69. Murray J, Singer E, Saxby F, French N (2004) Factors influencing risk of injury to horses falling during eventing. Veterinary Record 154(7): 207-208.

70. Murray JK, Singer ER, Morgan KL, Proundman CJ, French NP (2006) The risk of a horse-and-rider partnership falling on cross-country phase of eventing competition. Equine Veterinary Journal 38(2): 158163.

71. Nicholas MK, Blyth FM (2016) Are self-management strategies effective in chronic pain treatment? Pain management 6(1): 75-88.

72. Obelieniene D, Scrader H, Bovim G (1999) Pain after whiplash: A prospective controlled inception cohort study. J Neurol Neurosurg Psychiatry 66(3): 279-83.

73. O Brien D (2016) Look before you leap: what are the obstacles to risk calculation in the equestrian sport of eventing? Animals 6(2): 13.

74. O Brien D, Cripps RA (2008) Safety for Horses and Riders in Eventing. The SHARE Database; Rural Industries Research and Development Corporation p.1-69.

75. Paix BR (1999) Rider injury rates and emergency medical services at equestrian events. British Journal of Sports Medicine 33(1): 46-48.

76. Petróczi A, Naughton DP (2009) Popular drugs in sport: descriptive analysis of the enquiries made via the Drug Information Database (DID). British journal of sports medicine 43(11): 811-817.

77. Praemer A, Furnes S, Rice DP (1992) Musculoskeletal conditions in the United States. In: Anderson GBJ (1999) Epidemilogical features of chronic low-back pain. Lancet 354(9178): 581-585.

78. Radanov RP, Sturzenegger M, Di Stefano G (1996) Long-Term Outcome after Whiplash Injury: A 2-Year Follow-Up Considering Features of Injury Mechanism and Somatic, Radiologic, and Psychosocial Findings. Medicine 74(5): 281-297.

79. Roberts M, Shearman J, Marlin D(2009) A comparison of the metabolic cost of the three phases of the one-day event in female collegiate riders. Comparative Exercise Physiology 6(3): 129-135. 
80. Sandiford N, Buckle C, Alao U, Davison J, Richie J (2013) Injuries associated with recreational horse riding and changes over the last 20 years: A review. JRSM Short Rep 4(5).

81. Schmitt H, Hansmann HJ, Brocai DR, Loew M (2001) Long term changes of the throwing arm of former elite javelin throwers. International Journal of Sports Medicine 22(4): 275-279.

82. Schnur PL, Schnur DP, Petty PM, Weaver Al (1996) Reduction mammoplasty: An outcome study. Plast Reconstr Surg 100(4): 875883

83. Scurr J, White J, Hedger W (2009) Breast displacement in three dimensions during the walking and running gait cycle. Journal of Applied Biomechanics 25(4): 322-329.

84. Scurr J, White J, Hedger W (2010) Supported and unsupported breast displacement in three dimensions across treadmill activity levels. Journal of Sport Science 29(1): 55-61.

85. Shephard RJ (1997) Biology and Medicine in Sailing. Sports Medicine 23(6): 350-356

86. Singer ER, Saxby F, French N (2003) A retrospective case-control study of horse falls in the sport of horse trials and three-day eventing. Equine Veterinary Journal 35(2): 139-145.

87. Smartt P, Chalmers D (2009) A new look at horse-related sport and recreational injury in New Zealand. Journal of Science and Medicine in Sport 12(3): 376-382.

88. Telle C (2012) An investigation of the incidence of non-specific low back pain in competitive show jumping horse riders. Clinical Chiropractic 15(4): 196-197.
89. Terada K (2000) Comparison of head movement and EMG activity of muscles between advanced and novice horseback riders at different gaits. Journal of Equine Science 11(4): 83-90.

90. Theadom A, Parag V, Powell T, McPherson K, Starkey N, et al. (2016) Persistent problems 1 year after mild traumatic brain injury: A longitudinal population study in New Zealand. British Journal of General Practice 66(642): e16-e23.

91. Thompson K, Nesci C (2016) Over-riding concerns: Developing safe relations in the high-risk interspecies sport of eventing. International Review of Sociology in Sport p. 1-17.

92. Wahlström J, Hagber M, Toomingas A (2004) Percieved muscular tension, job strain, physical exposure, associations with neck pain among VDU users: A prospective cohort study. Occupation and Environment Medicine 61: 523-528.

93. Warson J, Hendrickson A (2007) The rider's pain free back. Trafalgar Square Books, Vermont, USA.

94. Wipper A (2000) The Partnership: The Horse-Rider Relationship in Eventing. Symbolic Interaction 23(1): 47-70.

95. Wolframm IA., Williams J, Marlin D (2015) The role of personality in equestrian sports: An investigation. Comparative Exercise Physiology 11(3): 133-144

96. Wood K, Cameron M, Fitzgerald K (2008) Breast size, bra fit and thoracic pain in young women: A correlational study. Chiropractic and Osteopathy 16: 1 .

\section{Your next submission with Juniper Publishers} will reach you the below assets

- Quality Editorial service

- Swift Peer Review

- Reprints availability

- E-prints Service

- Manuscript Podcast for convenient understanding

- Global attainment for your research

- Manuscript accessibility in different formats ( Pdf, E-pub, Full Text, Audio)

- Unceasing customer service

Track the below URL for one-step submission https://juniperpublishers.com/online-submission.php 